آناليز حساسيت و عدم قطعيت مدل WetSpa در

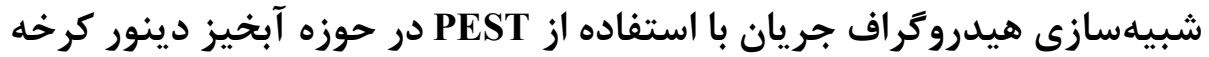

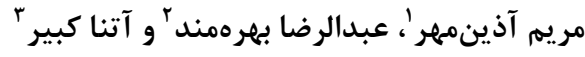

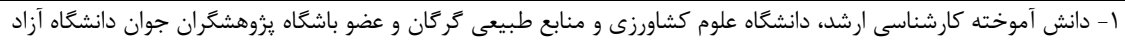

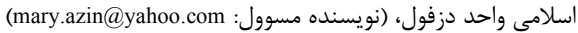

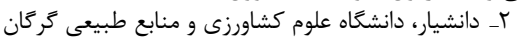

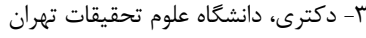

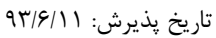

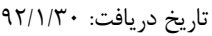

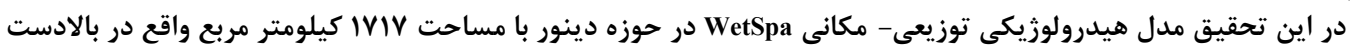

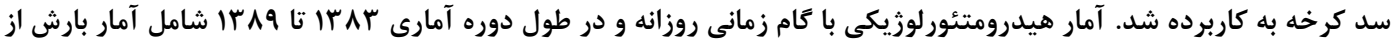

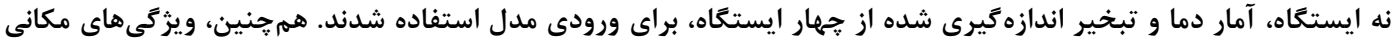

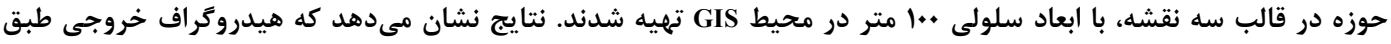

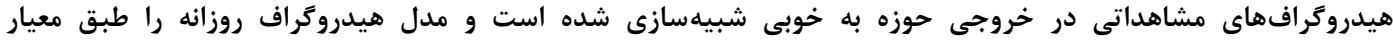

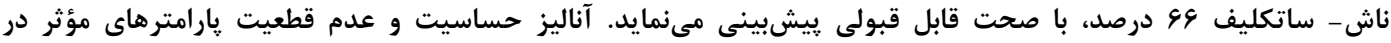

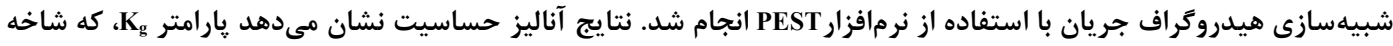

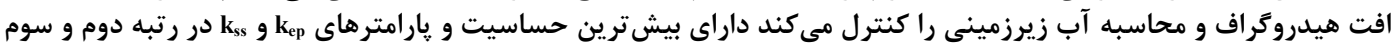

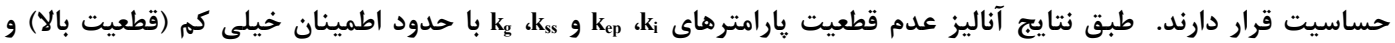

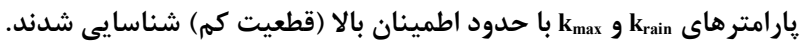

وازههاى كليدى: مدل WEST WetSpa، آناليز حساسيت، عدم قطعيت، شبيهسازى جريان، حوزه دينور، سد كرخه

يارامترها \&) تعيين منابع خطا لها ) قبل از كاربرد مدل

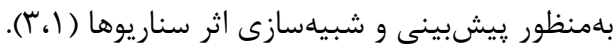

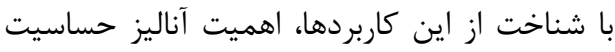

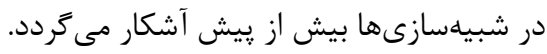

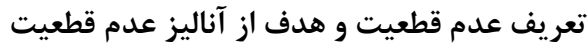

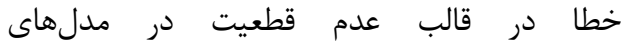

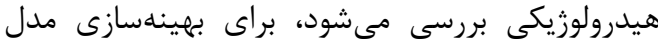

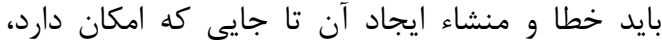

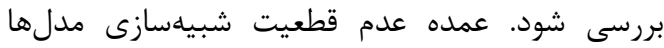

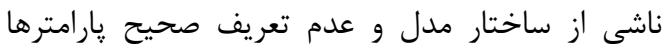

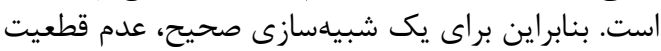

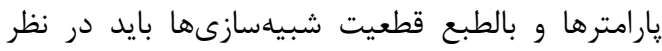

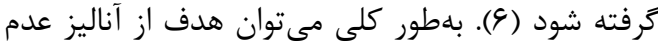

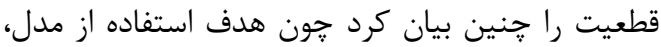

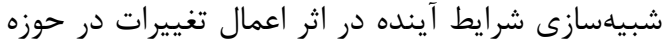

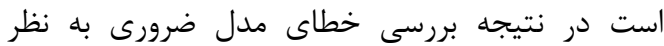

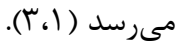

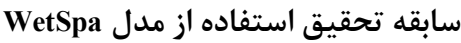

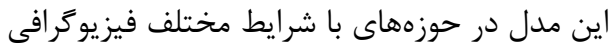

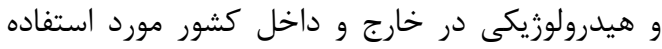

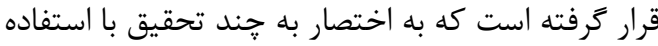

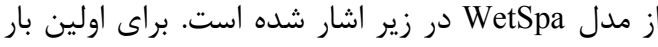

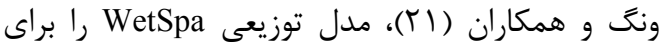

مقدمه

هدف از شبيهسازى پارامترها، مؤلفهها و نمودارهاى

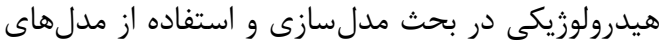

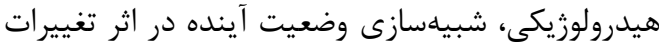

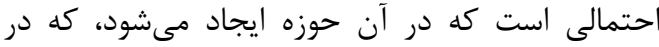

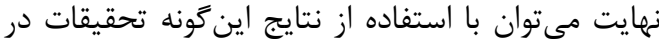

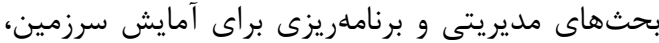

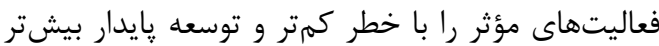

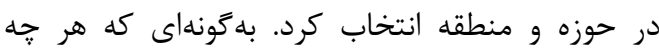

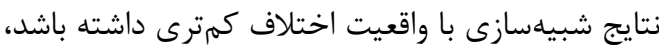

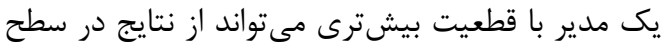

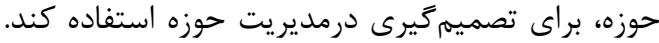

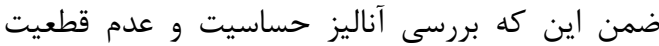

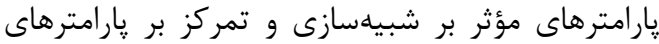

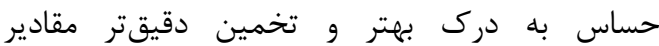

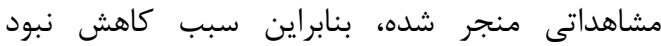

قطعيت در نتايج مدل مي كَر دد (19 (1). تعريف و اهميت آناليز حساسيت ميزان تغيير خروجى مدل به ازائ تغين تغيير در ميزان

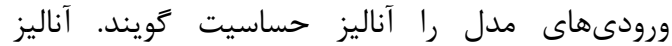

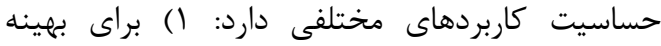

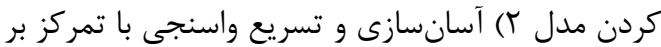

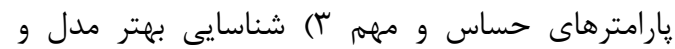


مدل PEST اشاره شده است. بهرهمند و دسمت (ז)، در

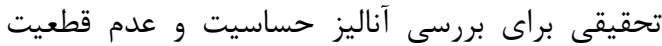

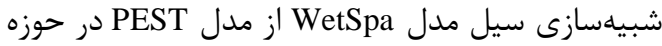

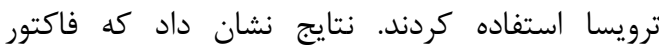

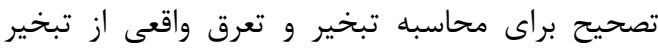

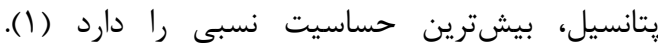

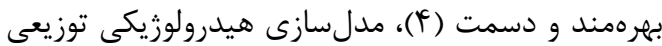

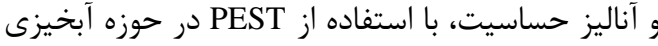

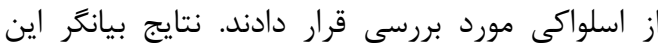

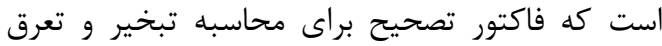

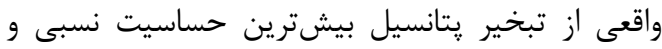

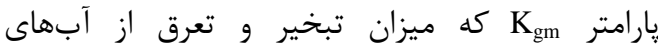

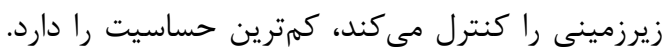

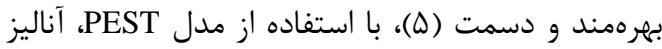

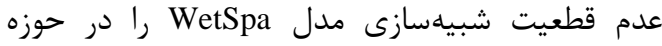
ترويسا بررسى كردند. طبق نتايج اين تحقيق ضريب فديب

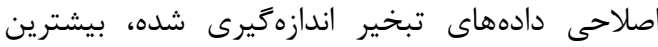

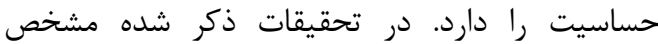

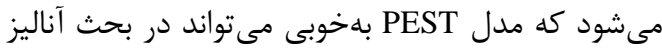

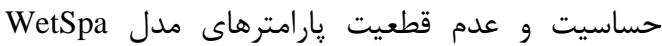
مورد استفاده قرار خيرد.

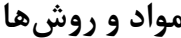
منطقه مورد مطالعه ورنه

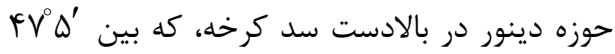

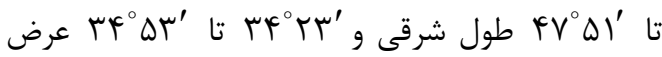
شمالى واقع در شمال شرق استان كرمانشاه است شكل

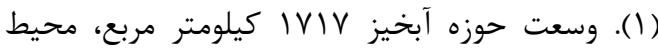

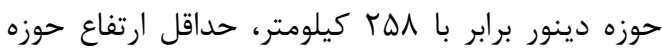

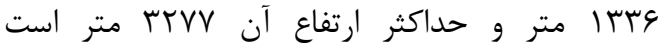

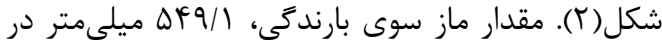

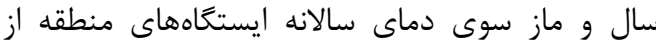

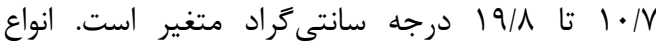

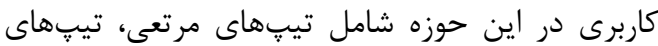

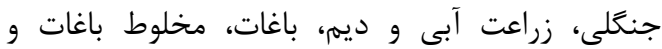

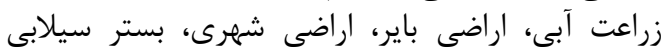

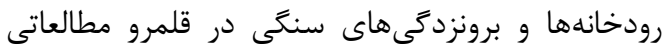

قابل ملاحظه است شكل (r).

تشريح مدل قابل ملاحطه است شيكل

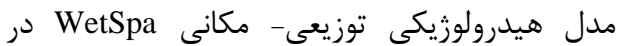

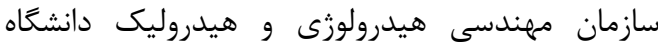

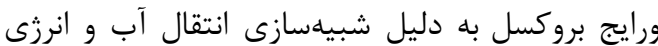

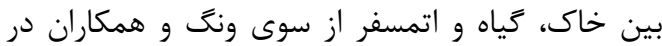

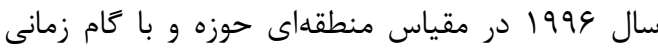

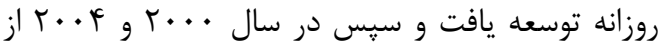

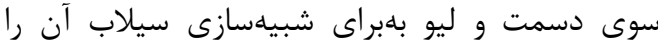
1- Terclep-Molenbic 4- Hornad

7- Parameter Solution

10- Shuffled Complex Evolution
شبيهسازى انتقال آب و انرزى بين خاك، گياهان و

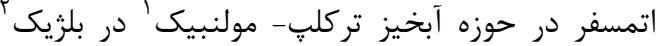

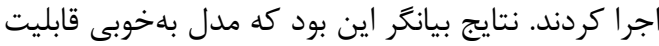

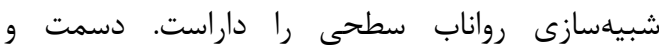

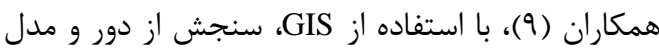

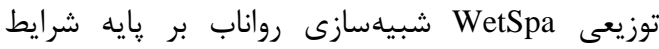

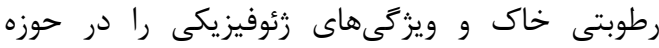

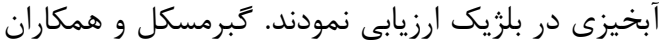

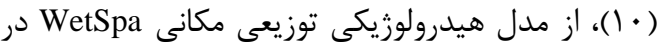

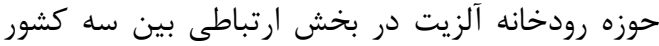

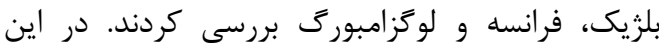

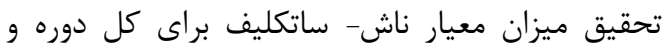

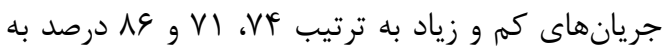

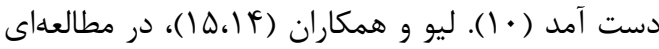

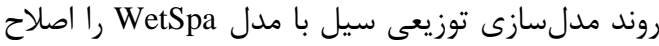

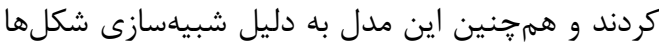

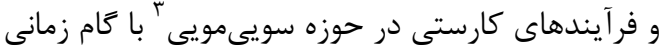

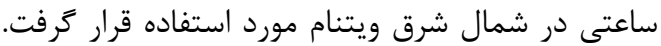

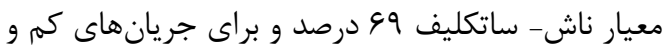

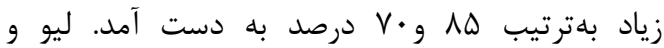

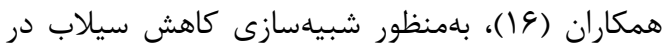

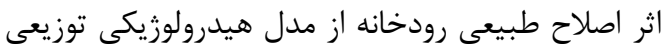
WetSpa

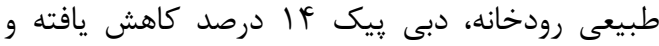

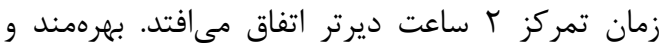

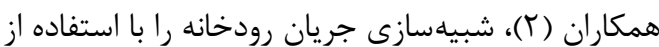

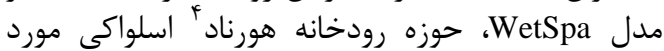

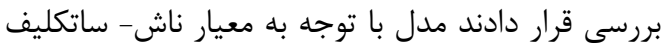

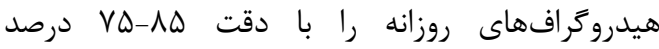

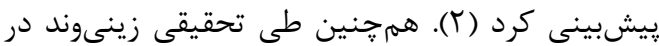

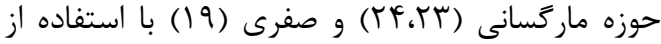

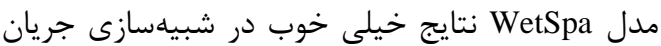

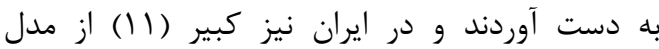
WetSpa

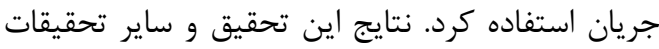

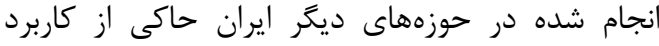

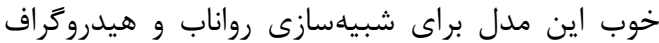

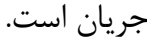
سابقه تحقيق استفاده از مدل PEST براى آناليز مدل WetSpa براى آناليز حساسيت و و عدم قطعيت مدلهاى

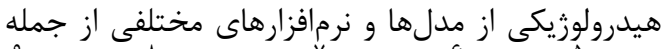

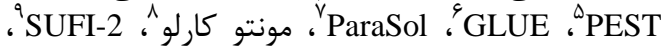
' و ... SCE

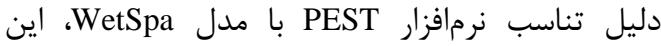

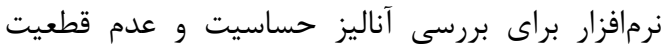

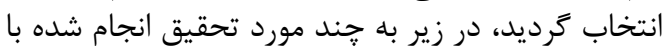
3- Souiemoi

6- Generalized Likelihood Uncertainty 9- Sequential Uncertainty Fitting 
اصلى، با استفاده از معادلات تقريب موج يخشى سنت و

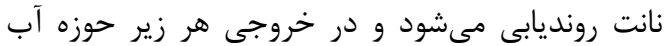

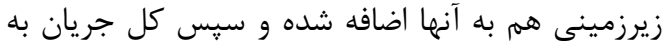

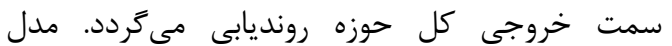
WetSpa

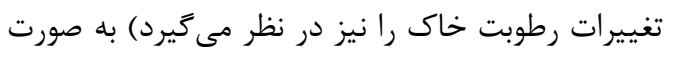

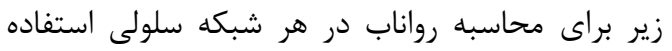
مى كند: $S=c_{i}(P-I)\left(\frac{\theta}{\theta_{S}}\right)^{a}$

(r) رابطه

كه S: رواناب سطحى يا بارش مازاد (ميلىمتر)، P: شبكه

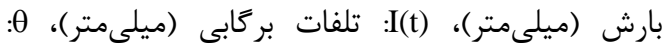
محتواى رطوبتى خاك (مترمكعب بر مترمكعب) و و رطوبت اشباع خاى (مترمكعب بر مترمكعب)، a a: توانى

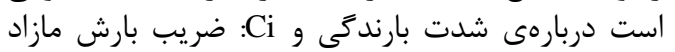

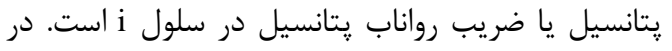

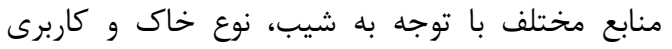

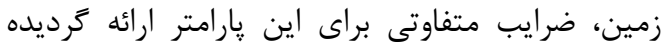

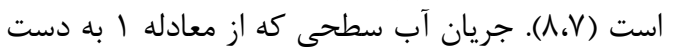

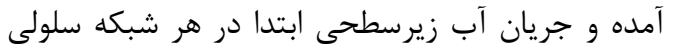

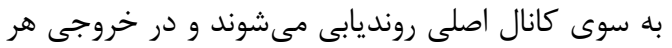

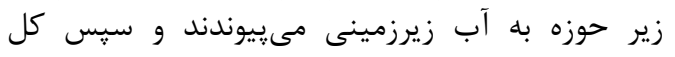

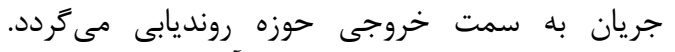

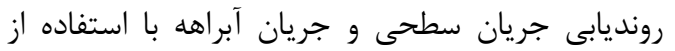

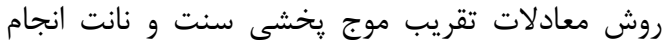

$$
\text { مى خيرد. }
$$

ليو و همكاران (ها)، براى محاسبه ميزان دبى در دري

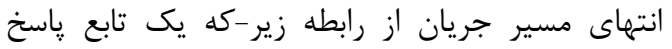
خطى سنت و نانت است - استفاده نمودند: رانيط زئر

$$
\mathrm{U}(\mathrm{t})=\frac{1}{\delta \sqrt{2 \pi \mathrm{t}^{3} / \mathrm{t}_{\mathrm{o}}^{3}}} \exp \left[-\frac{\left(\mathrm{t}-\mathrm{t}_{\mathrm{o}}\right)^{2}}{2 \delta^{2} \mathrm{t} / \mathrm{t}_{\mathrm{o}}}\right] \quad \text { (广) }
$$$$
t_{o}=\int \frac{1}{c} c d x
$$

$\sigma=\sqrt{\int \frac{2 d}{c^{3}} d x}$

(ه) (هابطه

كه در آن U (t) تابع ياسخ مسير جريان براى تعيين

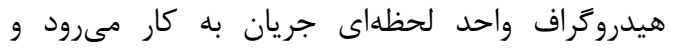

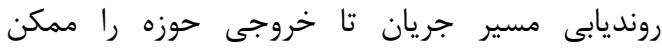

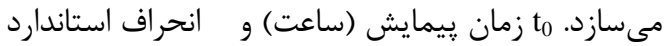

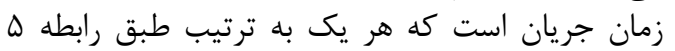

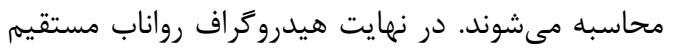

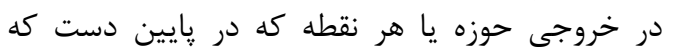

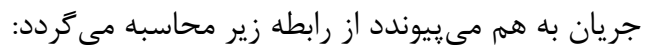
$\mathrm{Q}(\mathrm{t})=\int \mathrm{A} \int_{\mathrm{O}}^{\mathrm{t}} \mathrm{V}(\mathrm{t}) \mathrm{U}(\mathrm{T}-\tau) \mathrm{d} \tau \mathrm{dA}$

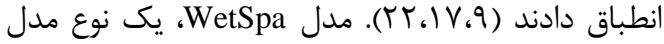

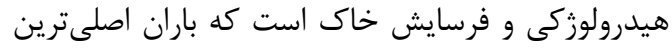

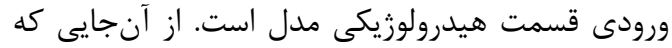

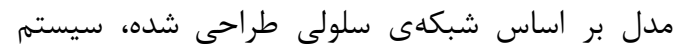

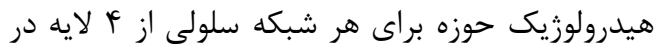

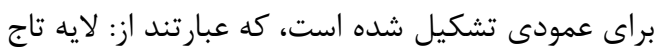

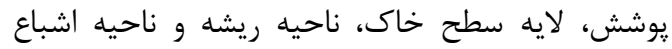

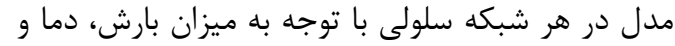

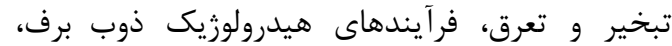

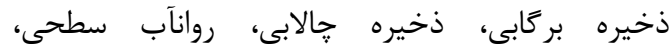

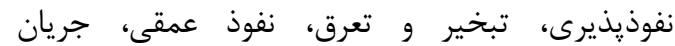

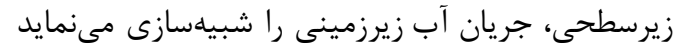

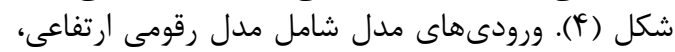

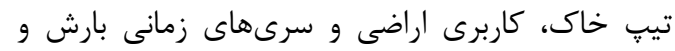

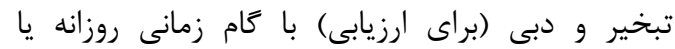

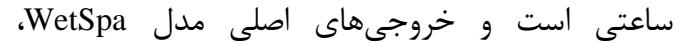

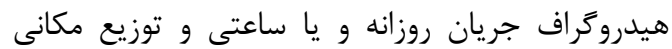

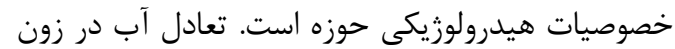

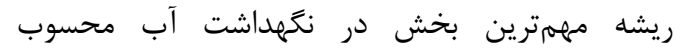

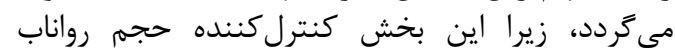

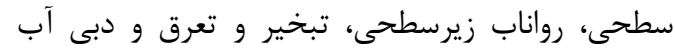

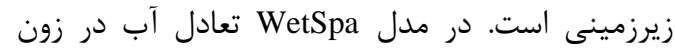
ريشه براى هر شبكه سلولى با توجه به درله رابطه زين $\mathrm{D}-\stackrel{\theta}{\mathrm{t}}=\mathrm{P}-\mathrm{I}-\mathrm{V}-\mathrm{E}-\mathrm{R}-\mathrm{F}$

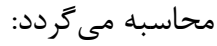
كه درآن D عمق ريشه (متر)، رطوبتى خاى (مترمكعب/ مترمكعب)، (روز)، P بارش (متر/ روز)، I=I تلفات اوليه

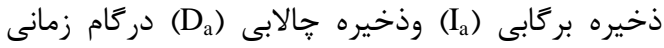

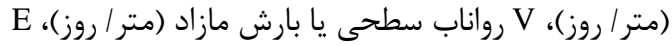

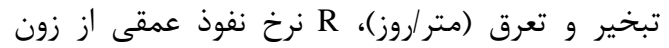

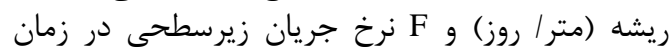

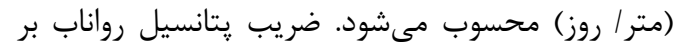

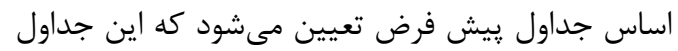

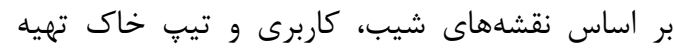

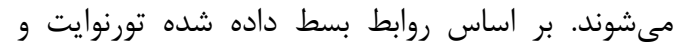

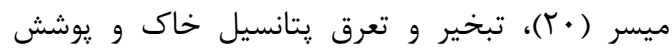

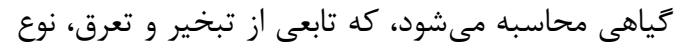

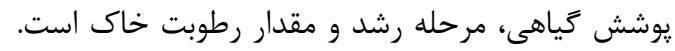

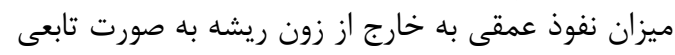

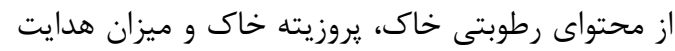

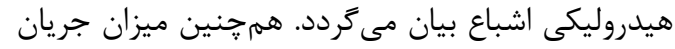

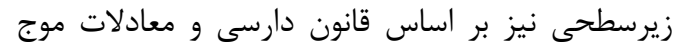

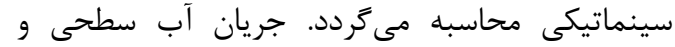

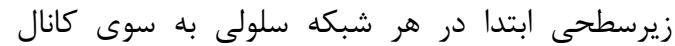




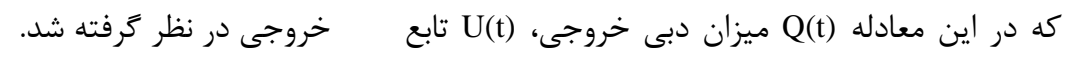

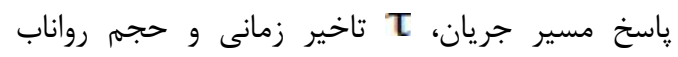
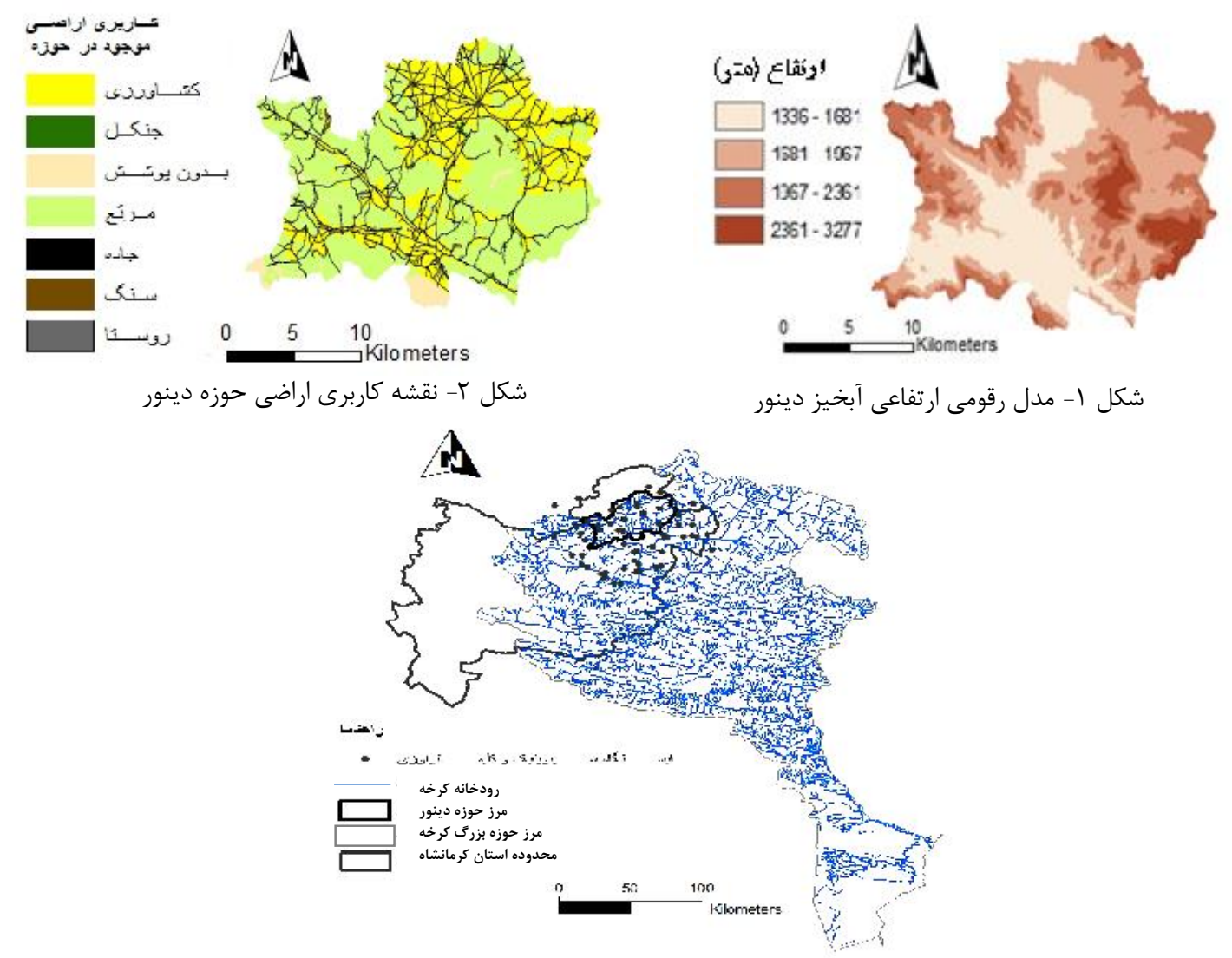

شكل r- محدوده آبخيز دينور در استان كرمانشاه بالادست سد كرخه.

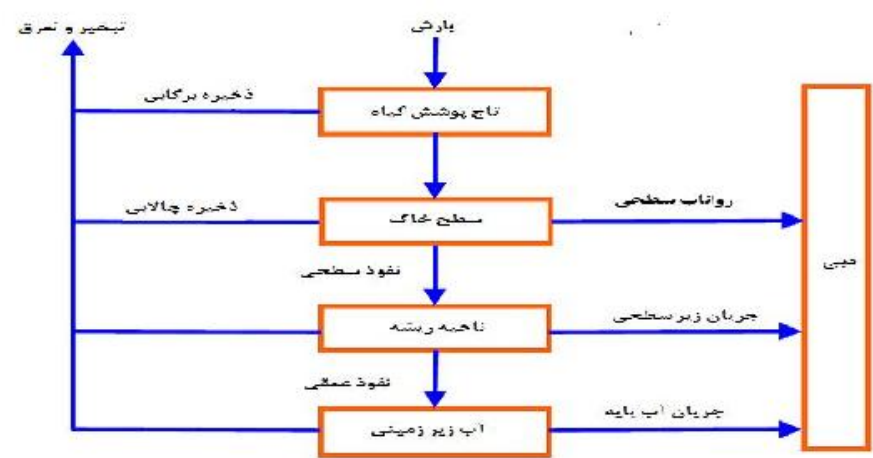

شكل ع- شماتيكى از دياكرام مدل WetSpa در مقياس سلول (1).

كاربرى اراضى، بافت خاك و مدل رقومى ارتفاعى در

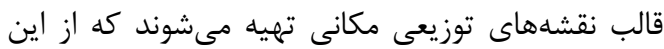

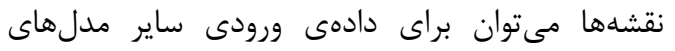

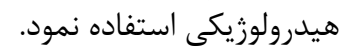

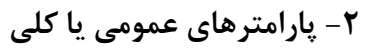

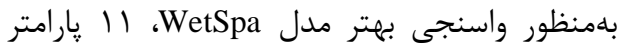
كلى در آن تعبيه شده است. اكثر اين يارامترها داراى

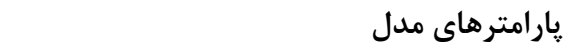

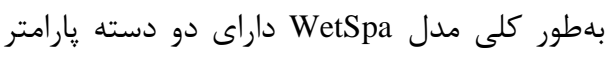

$$
\text { است كه در زير شرح داده مئش مدرد }
$$

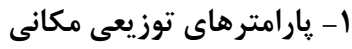

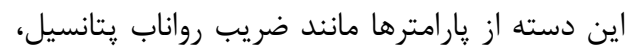

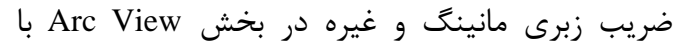
اجراى منوهاى مختلف و با استفاده از سه نقشه يايه 
9ـ حداكثر ذخيره آب زيرزمينى (k

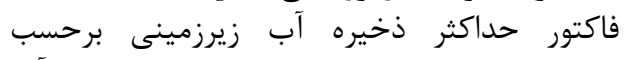

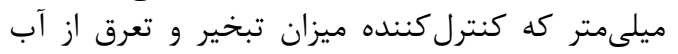

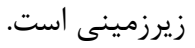

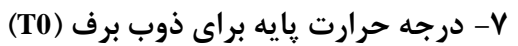

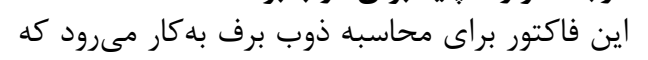

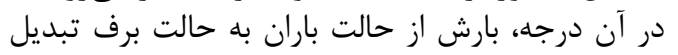

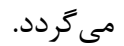

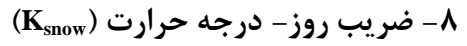

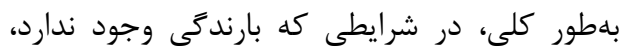

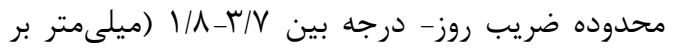

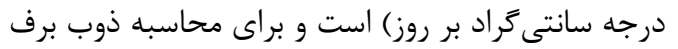

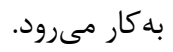

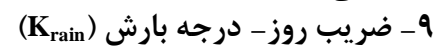

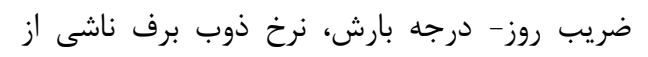

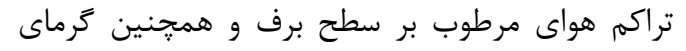

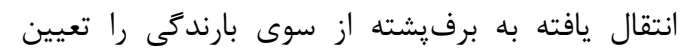

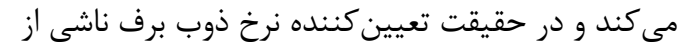

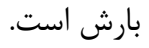
.ا- توان رواناب سطحى براى زمانى كه شدّت بارش به

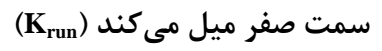

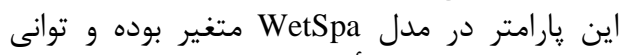

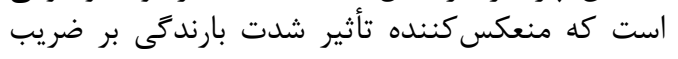

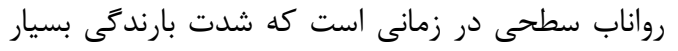

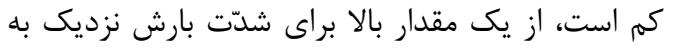

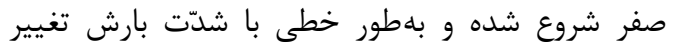

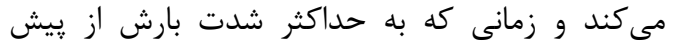
تعيين شده به يك مى مانى كلد بهد

(1)

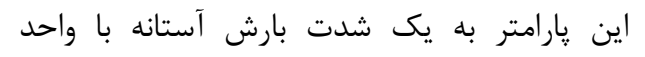

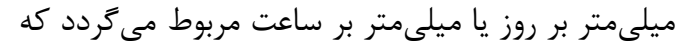

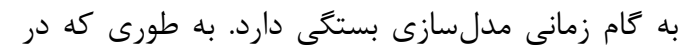

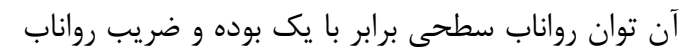

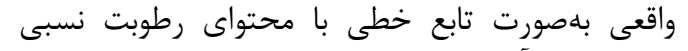

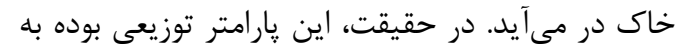

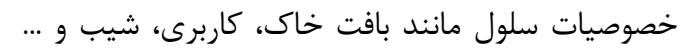

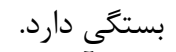

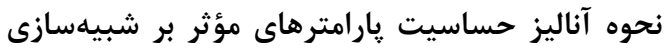

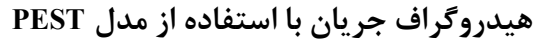

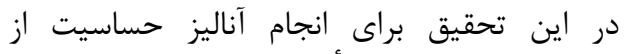

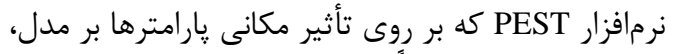

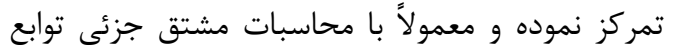

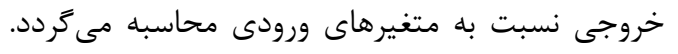

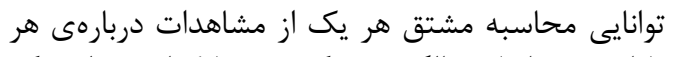

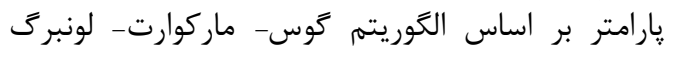

تعاريف فيزيكى بوده كه در كنترل رواناب و هيدروكراف

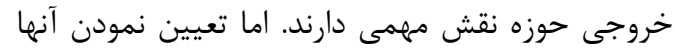

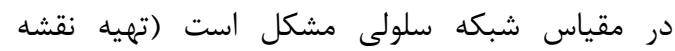

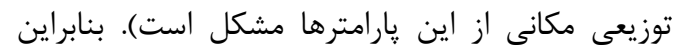

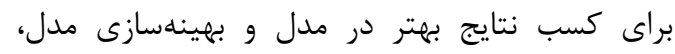

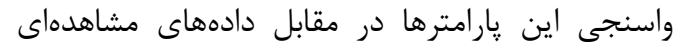

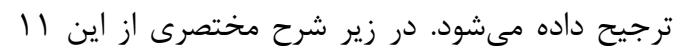
: إرارتر ذكر شده است:

1- فاكتور تصحيح تبخير و تعرق (k

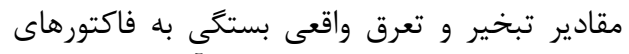

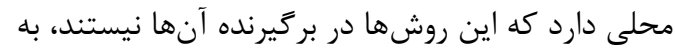

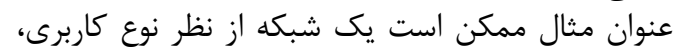

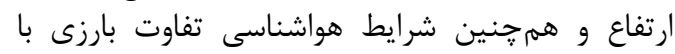

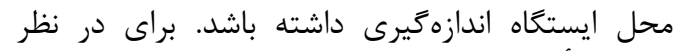

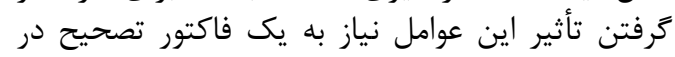

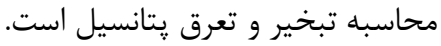

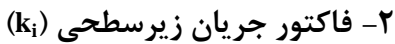

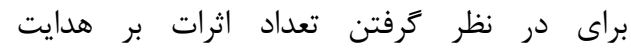

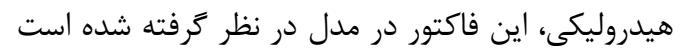

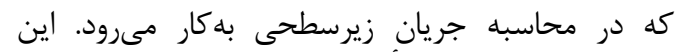

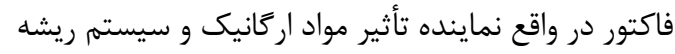

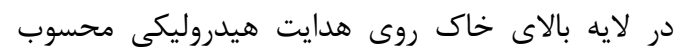

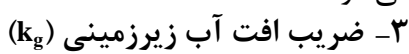

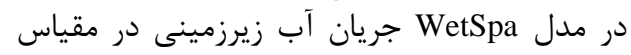

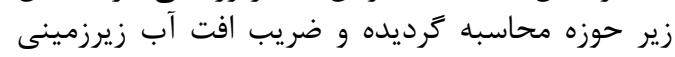

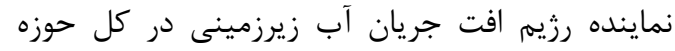

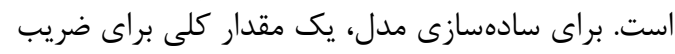

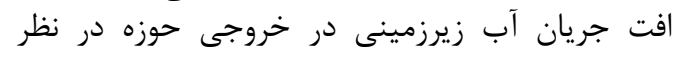

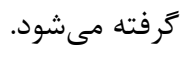

أF

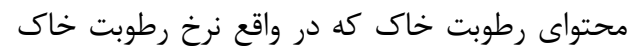

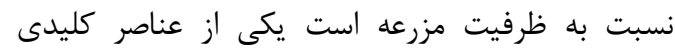

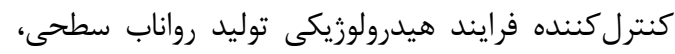

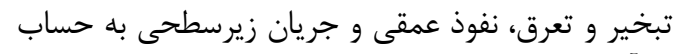

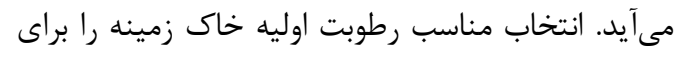

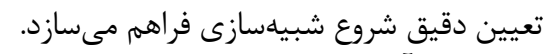

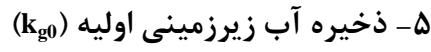

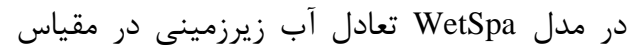

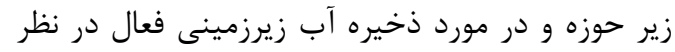

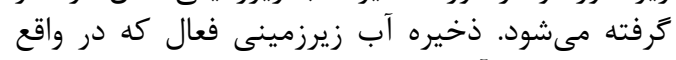

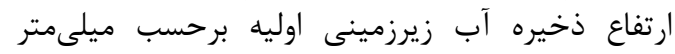

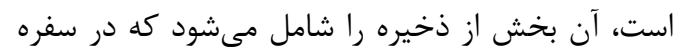

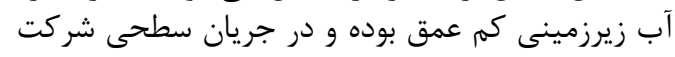
دارد. - مابر 
براى تعيين حدود اطمينان از مقادير مختلف هر هارامتر

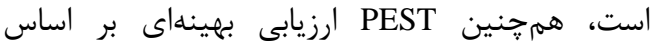

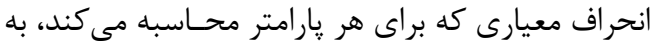

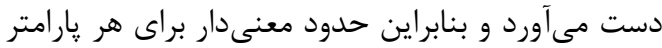

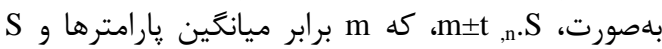

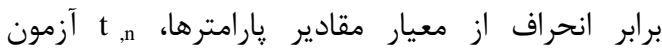

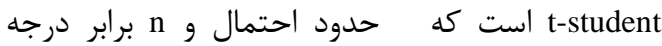

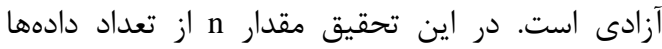

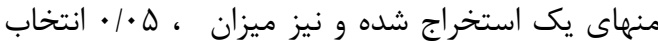

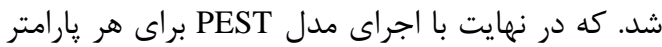

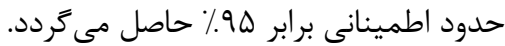

\section{نتايج و بحث}

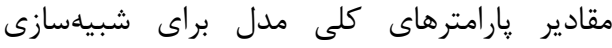
هيدروكراف جريان مقادير 11 يارامتر كلى برائ براى مرحله

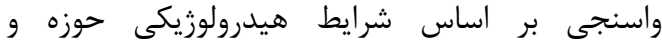
دستورالعمل مدل انتخاب شدهاند در جدول الرائيد ارئه شده
است كه در اين نرمافزار مورد استفاده قرار مى مئيرد.

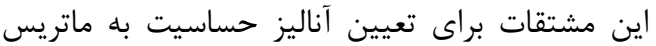

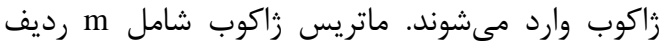

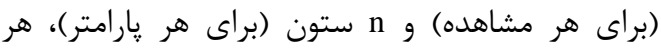

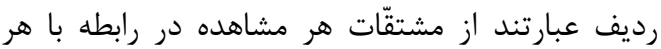

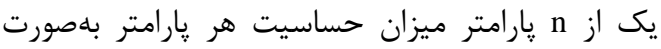

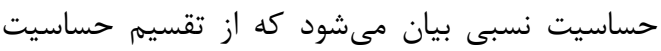

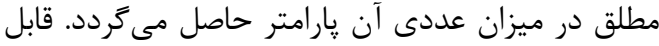

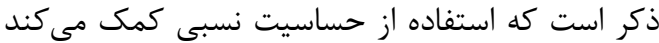

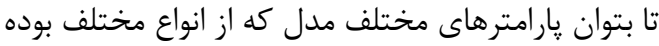

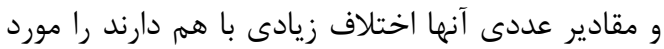
مقايسه قرار داد.

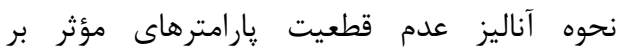

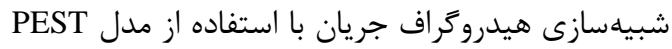

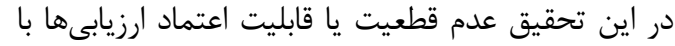

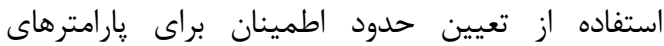

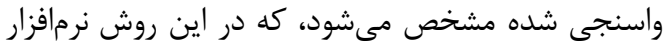

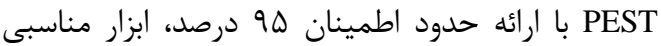

\begin{tabular}{|c|c|c|c|c|}
\hline 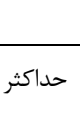 & اوليه & حداقل & ي مدل، مقادير اوليه و محدوده تغي & جدول \\
\hline $1 \cdot$ & $9 / V V \wedge$ & $\cdot / 1$ & فاكتور جريان زيرسطحى & $\overline{K_{\mathrm{i}}}$ \\
\hline$\cdot / 1$ & .1 .999 & $1 .-\infty$ & ضريب افت زيرزمينى (d-1 & $\mathrm{K}_{\mathrm{g}}$ \\
\hline r & $\cdot|9 \Delta|$ & $\cdot 11$ & رطوبت اوليه خاك (-) & $k_{\mathrm{ep}}$ \\
\hline r & $\cdot / I T F$ & $\cdot / \pi$ & فاكتور تصحيح تبخيرو تعرق يتانسيل (-) & $\mathrm{K}_{\mathrm{ss}}$ \\
\hline $1 \ldots$ & 1.199 & . & ذخيره آب زيرزمينى اوليه (mm) & $\mathrm{G}_{0}$ \\
\hline$r \cdots$ & $r \Delta \Delta / 99$ & $1 \cdots$ & حداكثر ذخيره آب زيرزمينى (mm) & $\mathrm{G}_{\max }$ \\
\hline r & I/DFT & r & ضريب درجه حرارت آستانه (Co & $\mathrm{T}_{0}$ \\
\hline$r / r$ & $\cdot / 4 R$ & $-r$ & 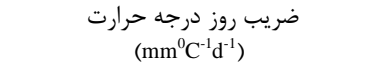 & $\mathrm{k}_{\text {snow }}$ \\
\hline$\cdot / r$ & $\cdot / \pi$ & $1 .^{-*}$ & 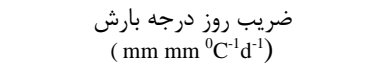 & $\mathrm{k}_{\text {rain }}$ \\
\hline$\checkmark$ & $V / 9 V V$ & f & توان رواناب سطحى (-) & $\mathrm{k}_{\mathrm{run}}$ \\
\hline$\Delta \cdots$ & $1 \cdots$ & $1 .$. & حداكثر شدت بارش (mm) & $\mathrm{p}_{\max }$ \\
\hline
\end{tabular}

آزمون كارايى مدل در دورههاى آمارى ديكر، آزمون

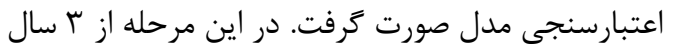

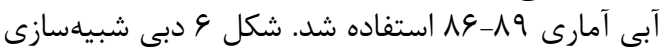

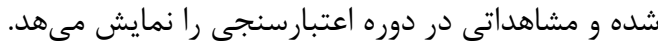

ارزيابى كارايى مدل WetSpa

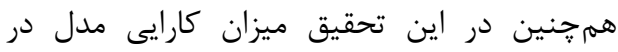

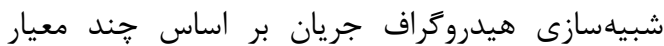

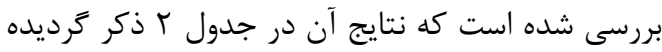

نتايج دوره واسنجى مدل WetSpa

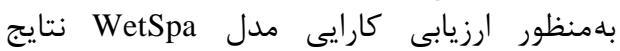

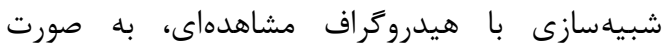

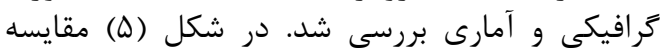

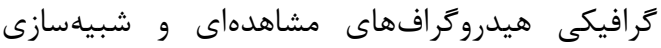

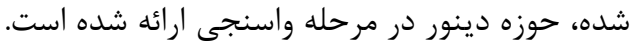

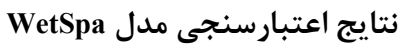

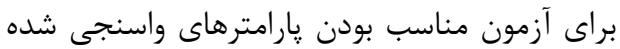

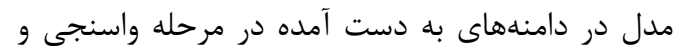




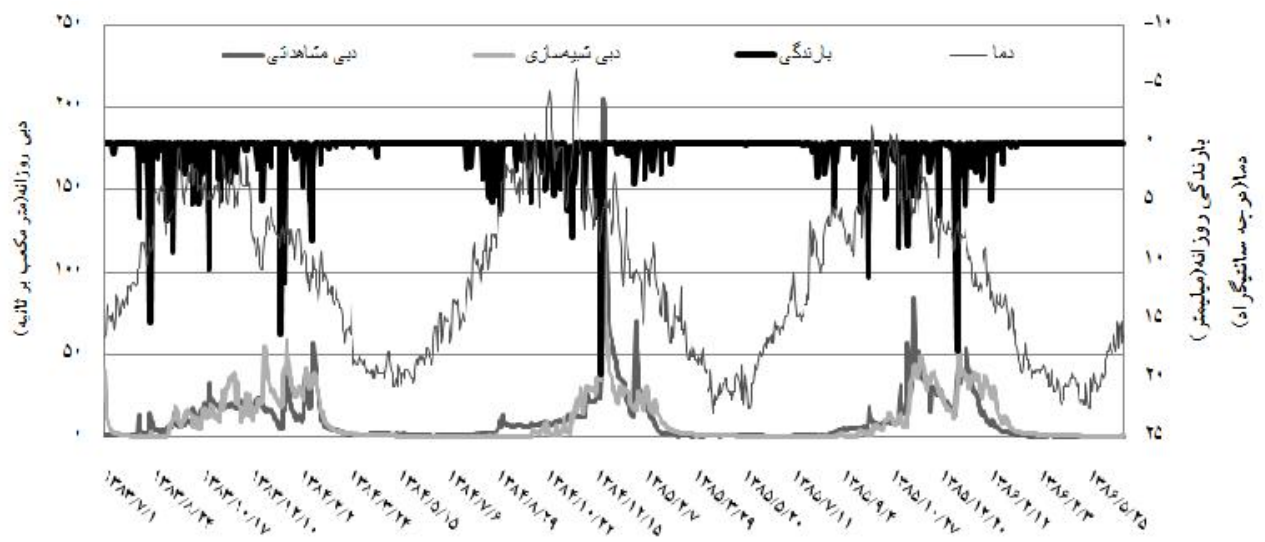

زمان(ن)

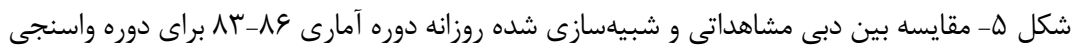

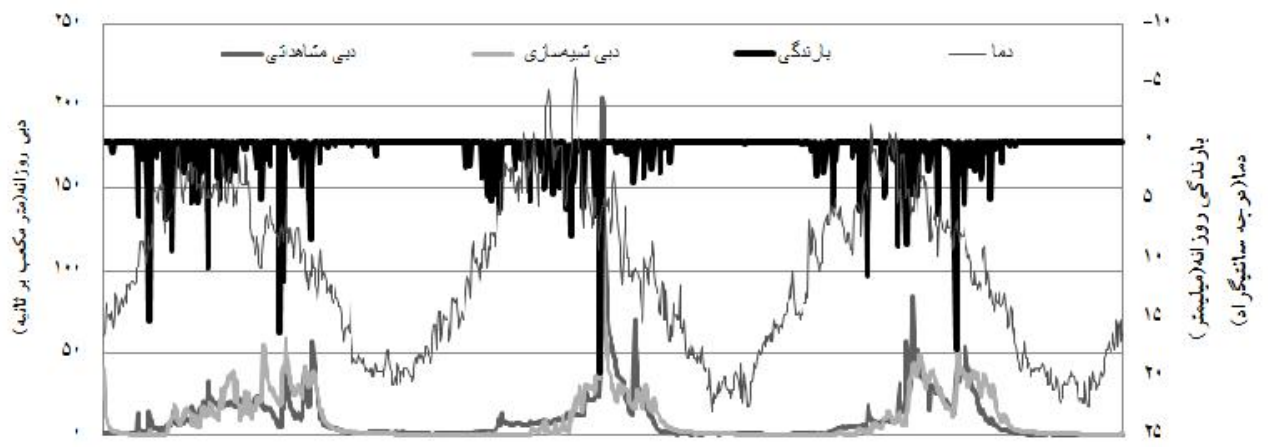

${ }_{12}$

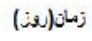

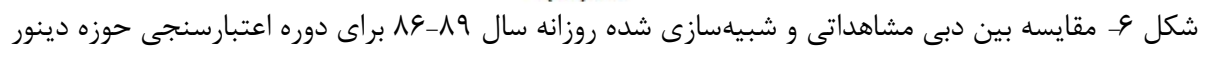

\begin{tabular}{|c|c|c|}
\hline اعتبارسنجى & واسنجى & 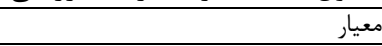 \\
\hline$\cdot / Q T$ & .199 & ناش- ساتكليف \\
\hline .194 & $\cdot 109$ & ناش- ساتكليف براى جريانهاى كم \\
\hline$\cdot 109$ & $\cdot / \mathrm{VT}$ & ناش- ساتكليف براى جريانهاى زياد \\
\hline$\cdot / \Delta \Delta$ & $-\cdot / \cdot \cdot r$ & خطاى مدل در محاسبه بيلان آبى (درصد) \\
\hline$\cdot / 49$ & $\cdot / \mathrm{VI}$ & معيار جمعى \\
\hline
\end{tabular}

شاخه آب زيرزمينى را كنترل مى كند داراى بيشترين

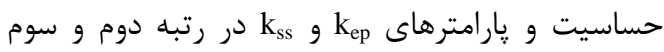

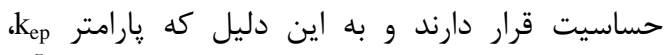

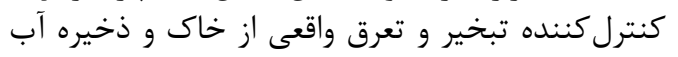

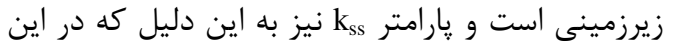

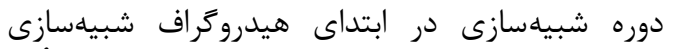

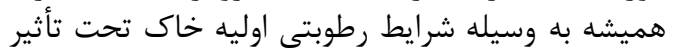

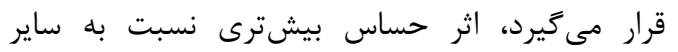

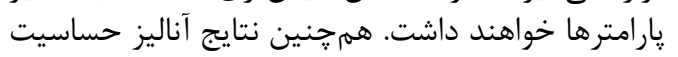

نتايج آناليز حساسيت يارامترهاى مدل WetSpa ذكر اين نكته ضراليز حساسيت بارامترهاي مدل كه نتايج آناليز

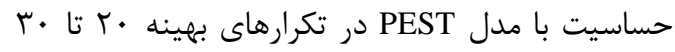

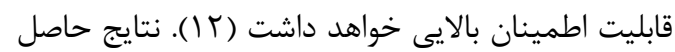

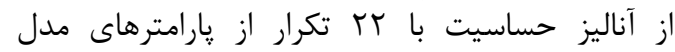
دetSpa

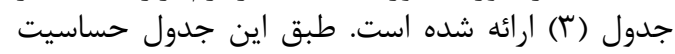

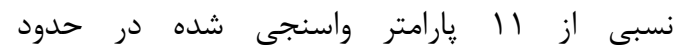

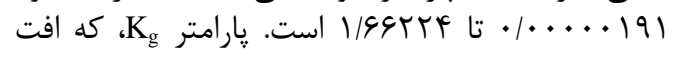


اطمينان يا عدم قطعيت متغيرها به وسيله فواصل يا

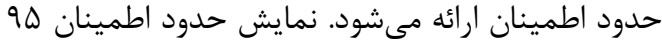

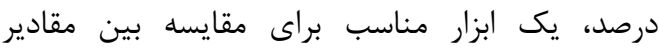
قطعيت يارامترهاى مختلف كه به وسيله

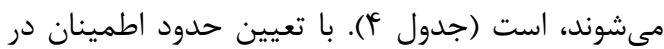

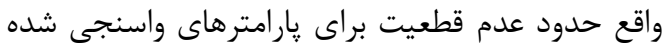

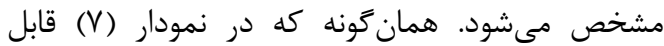

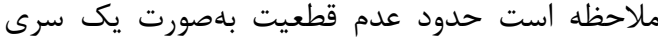
باند مشخص شده است.

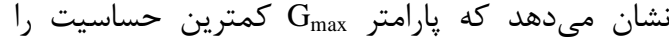

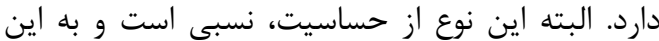

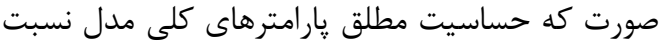

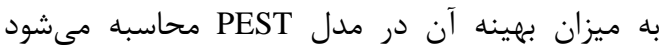

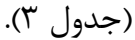

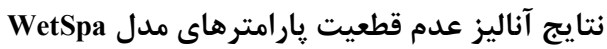

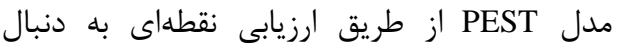

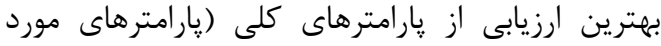

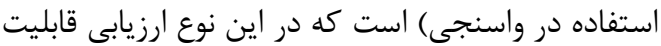

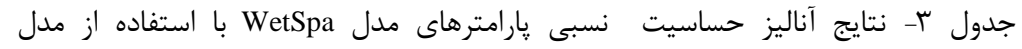

\begin{tabular}{|c|c|c|}
\hline رتبه (حساسيت نسبى) & حساسيت نسبى & علامت \\
\hline 1 & $\cdot / \cdot 1 V \lambda$ & $\mathrm{K}_{\mathrm{i}}$ \\
\hline 1 & 1/GGTYF & $\mathrm{K}_{\mathrm{g}}$ \\
\hline r & $\cdot / T \Delta Y \Lambda A V$ & $\mathrm{k}_{\mathrm{ep}}$ \\
\hline$r$ & - /QTTV.T & $\mathrm{K}_{\mathrm{ss}}$ \\
\hline 9 & $\cdot|\cdot| r \mid$ & $\mathrm{G}_{0}$ \\
\hline 11 & $1 / 91 \times 1 .^{-v}$ & $\mathrm{G}_{\max }$ \\
\hline 4 & . /.TAK & $\mathrm{T}_{0}$ \\
\hline$\Delta$ & . I. FTr & $\mathrm{k}_{\text {snow }}$ \\
\hline r & $\cdot / 1 A F$ & $\mathrm{k}_{\text {rain }}$ \\
\hline$\checkmark$ & - R. HIV & $\mathrm{k}_{\mathrm{run}}$ \\
\hline 1. & $\Delta / \Lambda \mid \times 1 \cdot \infty$ & $\mathrm{p}_{\max }$ \\
\hline
\end{tabular}

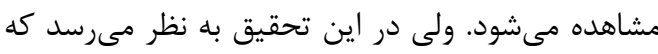

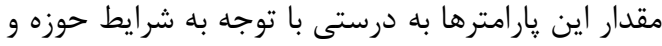

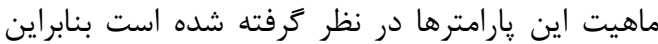

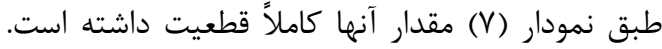

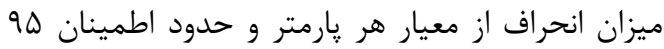

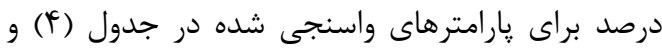

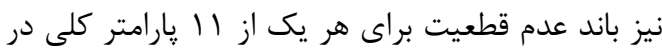
شكل V ارائه شده است.
مفهوم اين باندها بدين صورت است كه: يارامترهاى

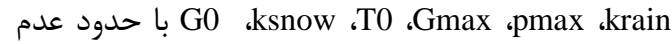
قطعيت بالا، يارامترهاى غير حساسى هستند كه تعيين

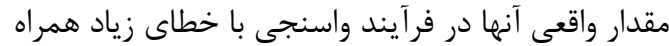

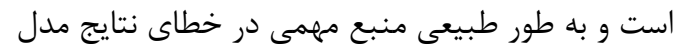

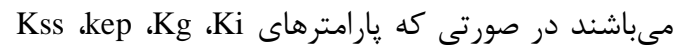

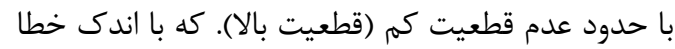

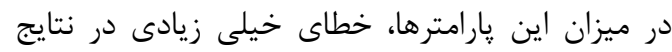

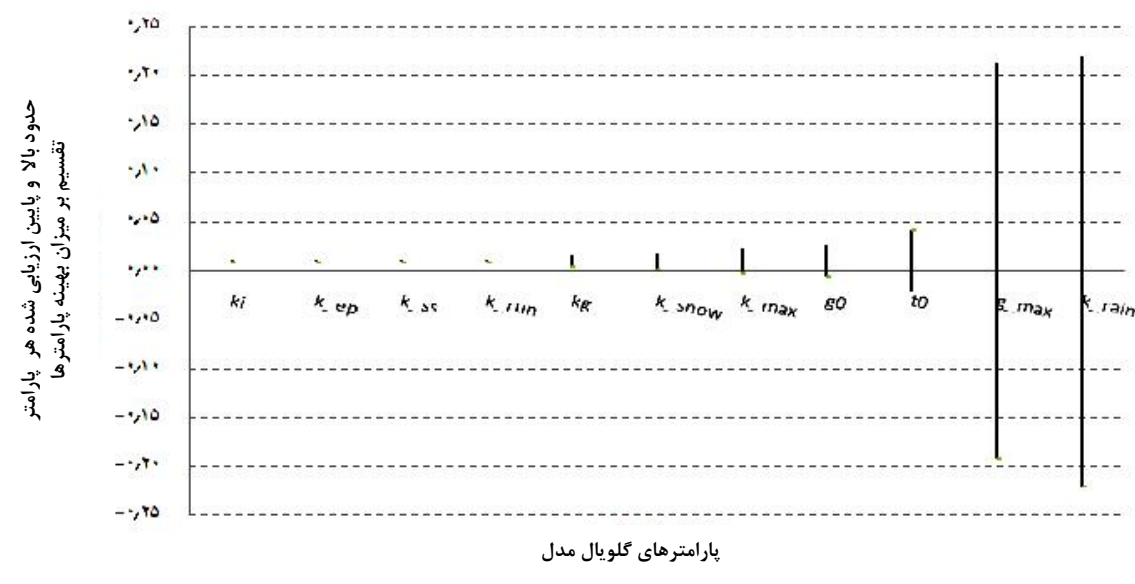

شكل V- محدوده عدم قطعيت هريك از يارامترهاى مدل WetSpa 


\begin{tabular}{|c|c|c|c|}
\hline $\begin{array}{r}\text { WetSpa } \\
\text { حداقل }\end{array}$ & م مداكثيت & انحراف از معيار هر پيارامتر & علامت \\
\hline $9 / 1<91$ & N/TMAT & - /NAFVGG & $\mathrm{K}_{\mathrm{i}}$ \\
\hline . /.१९६ & $\cdot \mid \cdot r \varepsilon \Lambda$ & . . म rast & $\mathrm{K}_{\mathrm{g}}$ \\
\hline • /MGQYF & - LAIVATE & $\cdot / \cdot r \Delta \Delta \Delta \Lambda$ & $\mathrm{k}_{\text {ep }}$ \\
\hline - /11frty & .119 .990 & $\cdot / \cdot 1 T \cdot 91$ & $\mathrm{~K}_{\mathrm{ss}}$ \\
\hline$-r / 9 V \mid \Delta T$ & rY/DQYq & 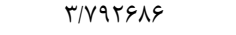 & $\mathrm{G}_{0}$ \\
\hline$-94 / \% \wedge$ & $1 / 9 \cdot \uparrow \wedge$ & $T r \cdot T / 91$ & $\mathrm{G}_{\max }$ \\
\hline - -ATTMA & - /ATaVbA & $\cdot$. DSTVV & $\mathrm{T}_{0}$ \\
\hline$\cdot / \cdot V A T$ & - /qF\&DFA & $\cdot \mid \cdot 9 \mu 1 \cdot \Delta$ & $\mathrm{k}_{\text {snow }}$ \\
\hline $.1 .9 V r$ & $.1 .9 V \mathrm{~F}$ & |... & $\mathrm{k}_{\text {rain }}$ \\
\hline$\Delta / / T \cdot V \Lambda$ & $V / r \Lambda \& V \Lambda$ & $\cdot / 1 \cdot v \cdot \Delta$ & $\mathrm{k}_{\text {run }}$ \\
\hline$-\Lambda \cdot / \Delta \Delta V \mu$ & $V|\varepsilon / F \Delta|$ & $\Delta T / T Y V V T$ & $p_{\max }$ \\
\hline
\end{tabular}

PEST

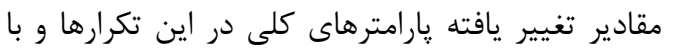
انجام آزمون

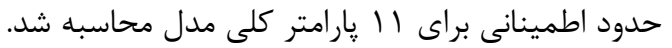

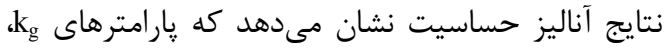

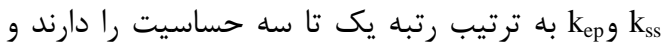

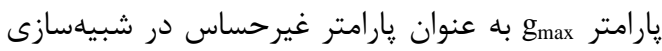

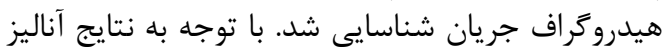

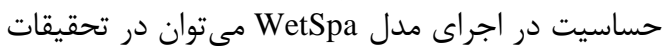

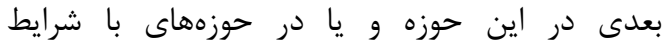

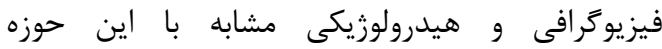

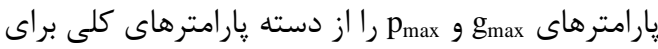

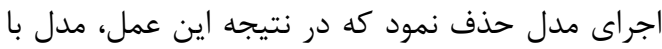

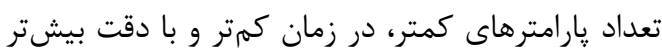

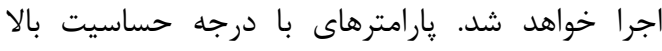

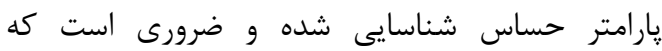

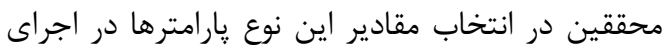

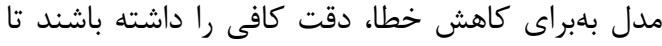

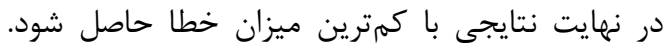

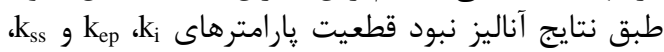

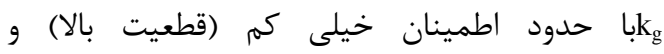

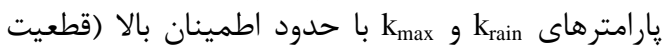

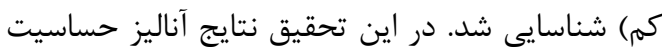

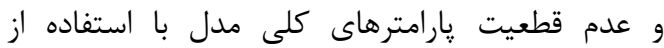

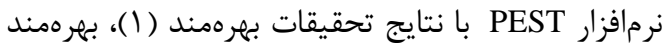

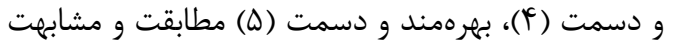

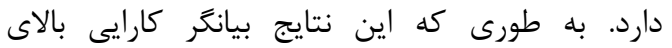

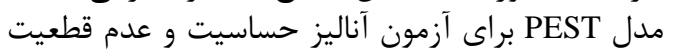
يارامترهاى كلى مدل WetSpa محسوب آناليز حساسيت مئود.

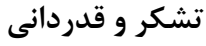

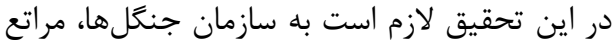

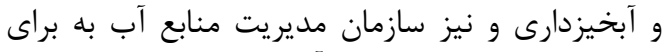

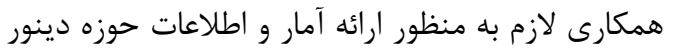

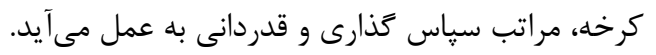

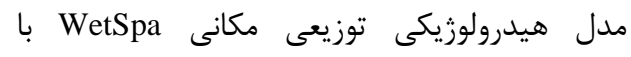

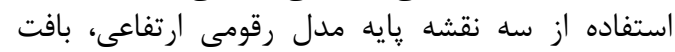

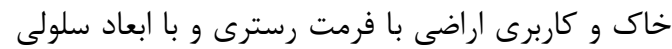

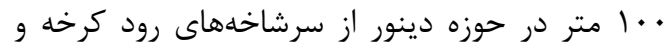

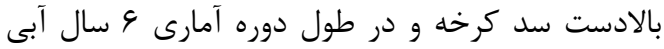

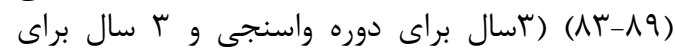

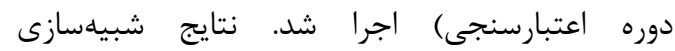

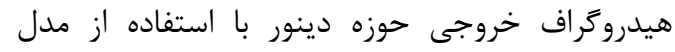
هيدرولوزيكى توزيعى مكانى ارزيابى ميىشود و اين مؤيد قابليت بسيار خوب ايني اين مدلي

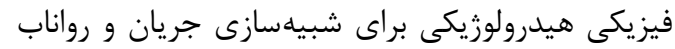

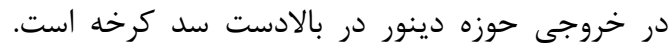

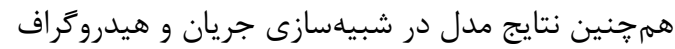

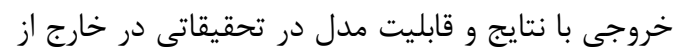

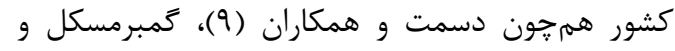

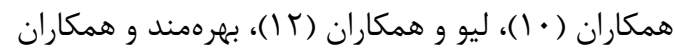

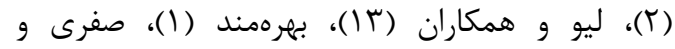

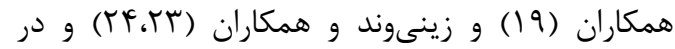

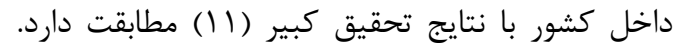

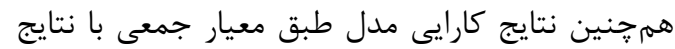

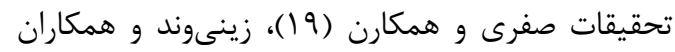

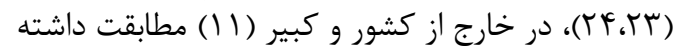

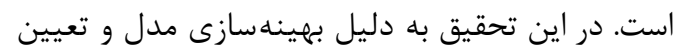

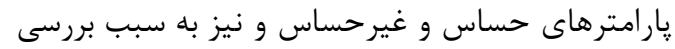

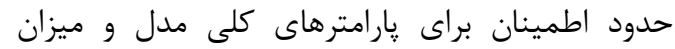

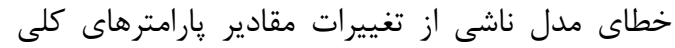

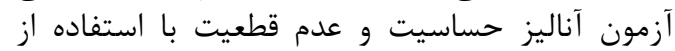

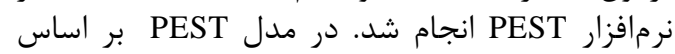

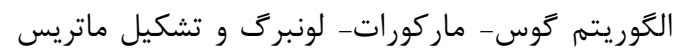

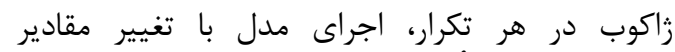

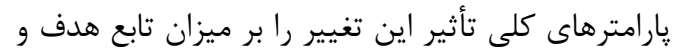

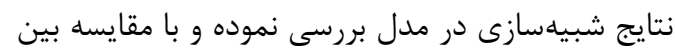

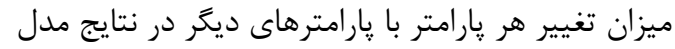

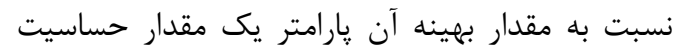

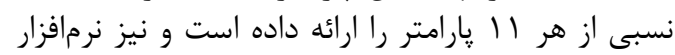


1. Bahremand, A. 2006. Simulating the Effects of Reforestation on Floods Using Spatially Distributed Hydrologic Modeling and GIS. PhD Thesis. Vrije University Brussel Belgium. $150 \mathrm{pp}$.

2. Bahremand, A., J. Corluy, Y.B. Liu and F. De Smedt. 2006. Stream Flow Simulation by WetSpa Model in Hornad River Basin, Slovakia, Floods, from Defence to Management-Van Alphen, van Beek \&Taal (eds), Taylor \& Francis Group, London 67-74.

3. Bahremand, A., F. De Smedt, J. Corluy, Y.B. Liu, J. Poorova, L. Velcicka and E. Kunikova. 2007. WetSpa Model Application for Assessing Reforestation Impacts on Floods in Margecany-Hornad Watershed, Slovakia. Journal of Water Resources Management, 22: 393-408.

4. Bahremand, A. and F. De Smedt. 2008. Distributd hydrological modeling and sensitivity and uncertainty analysis in Torysa watershed, Slovakia. Journal of Water Resources Management, 22: 393-408.

5. Bahremand, A. and F. De Smedt. 2010. Predictive Analysis and Simulation Uncertainty of a Distributed Hydrological Model. Journal of Water Resources Management, 24: 2869-2880.

6. Beven, K.J. and A. Binley. 1992. The Future of Distributed Models: Model Calibration and Uncertainty Prediction. Journal of Hydrological Processes, 6: 279-298.

7. Browne, F.X. 1990. Stormwater Management, Standard Handbook of Environmental Engineering, R.A. corbitt (ed.), McGraw-Hill, The McGraw-Hill Companies, Inc. ISBN: 9780070131606.

8. Chow, V.T., D.R. Maidment and L.W. Mays. 1988. Applied Hydrology, McGraw-Hill, New York. $136 \mathrm{pp}$.

9. De Smedt, F., Y.B. Liu, S. Gebremeskel. 2000. Hydrological Modeling on a Catchment Scale Using GIS and Remote Sensed Land Use Information, in: C.A. Brebbia (ed.), Risk Analysis II, WTI press, Boston, 137: 295-304.

10. Gebremeskel, S., Y.B. Liu and F. De Smedt. 2002. GIS Based Distributed Modeling for Flood Estimation, Proceeding of th Twenty-Second Annual American Geophysical Union Hydrology Days. $11 \mathrm{pp}$.

11. Kabir, A. 2011. Aapplication and Development of a Spatially Distributed Hydrologic Model WetSpa for Stream Flow Simulation in Gorganrood River Watershed, Golestan Province. PhD Thesis, Islamic Azad University of Tehran, Sciences and Rrsearch Branch, 300 pp.

12. Liu, Y.B., O. Batelaan and F. De Smedt. 2005. Automated Calibration Applied to a GIS-Based Flood Simulation Model Using PEST. Taylor \& Francis Group, London, , ISBN 041538050 2. 317-326.

13. Liu, Y.B., J. Corluy, A. Bahremand, F. De Smedt and J. Poórová. 2006. Simulation of Runoff and Phosphorus Transport in a Carpathian Catchment, Slovakia. Journal of River Research and Applications ournal (accepted), pp: 317-326.

14. Liu, Y.B., O. Batelaan, F. De Smedt, N.T. Huong and V.T. Tam. 2005b. Test of a Distributed Modelling Approach to Predict Flood Flows in the Karst Suoimuoi Catchment in Vietnam. Journal of Environmental Geology. 48: 931-940.

15. Liu, Y.B., S. Gebremeskel, F. De Smedt, L. Hoffmann and L. Pfister. 2003. A Diffusive Transport Approach for Flow Routing in GIS-Based Flood modeling. Journal of hydrology, 283: 91-106.

16. Liu, Y.B. 2004. Development and Application of a GIS-Based Hydrological Model for Flood Prediction and Watershed Management. PhD Thesis. Brussel Belgium: Vrije University Brussel Belgium. 185 pp.

17. Liu, Y.B. and F. De Smedt. 2004. WetSpa Extension, Documentation and User Manual, Department of Hydrology and Hydraulic Engineering. Brussel. Brussels: Vrije University Brussel Belgium. 200 pp.

18. Lenhart, T., K. Eckhardt, N. Fohrer and H.G. Frede. 2002. Comparison of Two Different Approaches of Sensitivity Analysis, Journal of Physics and Chemistry of the Earth, 27: 645-654.

19. Safari, A., F. De Smedt and F. Moreda. 2009. WetSpa Model Application in the Distributed Model Intercomparison Project (DMIP2). Journal of Hydrology, 419: 78-79.

20. Thornthwaite and J.R. Mather, 1955. The water balance. Publications in Climatology, Vol. 8, No. 1, pp: $5-86$.

21. Wang, Z.M., O. Batelaan and F. De Smedt. 1996. A Distributed Model for Water and Energy Transfer between Soil, Plants and Atmosphere (WetSpa). Journal of Physics and Chemistry of the Earth, 21: 189-193.

22. Wang, Z., O. Batelaan and F. De Smedt. 1997. Adistributed Model for Wate and Energy Transfer between Soil, Plants and Atmosphere (WetSpa). Journal of Physics and Chemistry of the Earth, 21: 189-193.

23. Zeinivand, H. 2009. Development of Spatially Distributed Hydrological WetSpa Modules for Snowmelt, Soil Erosion and Sediment Transport PhD Thesis. Brussel Belgium: Vrije Universiteit. 150 pp.

24. Zeinivand, H. and F. De Smedt. 2009. Prediction of snowmelt floods with a distributed hydrological model using a physical snow mass and energy balance approach. Journal of Natutal Hazards, DOI 0.1007/s11069-009-9478-9. 


\title{
Parameter Sensitivity and Uncertainty Analysis of the Model WetSpa in the Flow Hydrograph Simulation Using PEST, in Dinvar Basin, Karkheh
}

\author{
Maryam Azinmehr ${ }^{1}$, Abdolreza Bahremand ${ }^{2}$ and Atena Kabir ${ }^{3}$ \\ 1- Graduated M.Sc., Young Researcher and Elite club, Dezful Branch, Eslamic Azad University, \\ Khouzestan, lran (Corresponding author: mary.azin@yahoo.com) \\ 2- Associate Professor, Gorgan University of Agricultural Sciences and Natural Resources \\ 3- Ph.D., Sciences and Research Branch Islamic Azad University of Tehran \\ Received: April 19, $2013 \quad$ Accepted: September 2, 2014
}

\begin{abstract}
The spatially distributed hydrologic model WetSpa is applied to the Dinvar river basin (1717 $\mathrm{km}^{2}$ ) located in upstream of the Karkheh Dam. Daily hydrometeorological data from 1382 to 1389, including precipitation data from 9 stations, temperature and evaporation data measured at 4 stations are used as input to the model. The spatial characteristic of the basin is described by three base maps, i.e. DEM, land use and soil type, in GIS form using $100 \mathrm{~m}$ cell size. Results of the simulations show a good agreement between calculated and measured hydrographs at the outlet of the basin. The model predicts the daily discharge values with a good accuracy, i.e. about $66 \%$ according to the Nash-Sutcliff criterion. Sensitivity and uncertainty analysis of the model parameters is performed using a model-independent parameter estimator, PEST. It is found that the correction factor for calculating the groundwater flow recession coefficient has the highest relative sensitivity and the parameters kss and kep located in two and three ranks of the relative sensitivity. Parameter uncertainty analysis shows that parameters ki; kep, kss and kg have high certainty and as well as parameters krain, kmax have low certainty.
\end{abstract}

Keywords: Dinvar Basin, Flow Simulation, Karkheh Dam, PEST, Sensitivity Analysis, Uncertainty, WetSpa Model 